\title{
The Chartographer of Hysteria and Fibromyalgia Tender Points
}

\author{
Francesco BRIGO \\ Department of Neurological and Movement Sciences, University of Verona, Verona, Italy
}

A relevant component of the now largely discredited theory of hysteria, developed by the French neurologist Jean-Martin Charcot in the $19^{\text {th }}$ century, was the concept of the "hysterogenic zones". These zones were defined by Charcot as "more or less circumscribed regions of the body on which pressure or simple rubbing produces quite readily the phenomenon of aura, and which, if you persist, may be followed by the hysterical attack. These points or patches may in addition be the site of permanent hypersensibility and, before an attack, of spontaneous painful irritation". ${ }^{1}$ During his lifelong studies on hysteria, Charcot conducted a thorough examination with each patient, managing to plot the distribution of these hysterogenic points on a body chart.

It is astonishing to consider that most hysterogenic zones identified by Charcot below the clavicle, in the submammary region, at the bottom of the rib cage, across the anterior surface of the body trunk, and between the shoulder blades, largely correspond to fibromyalgia's tender points, localized areas of tenderness on palpation which, in patients with at least a three-month history of diffuse musculoskeletal pain, represent diagnostic standard for fibromyalgia. ${ }^{2}$

It is therefore tempting to speculate that, at least in some cases, Charcot's patients were affected by the disorder we nowadays would call "fibromyalgia".

\section{Declaration of conflicting interests}

The author declared no conflicts of interest with respect to the authorship and/or publication of this article.

\section{Funding}

The author received no financial support for the research and/or authorship of this article.

\section{REFERENCES}

1. Micale MS. Hysterical men: The Hidden History of Male Nervous Illness. Cambridge, MA: Harvard University Press; 2008. p. 153.

2. Wolfe F, Smythe HA, Yunus MB, Bennett RM, Bombardier C, Goldenberg DL, et al. The American College of Rheumatology 1990 Criteria for the Classification of Fibromyalgia. Report of the Multicenter Criteria Committee. Arthritis Rheum 1990;33:160-72.

Received: November 21, 2013 Accepted: November 21, 2013

Correspondence: Francesco Brigo, M.D. Department of Neurological and Movement Sciences, University of Verona, 37134 Verona, Italy.

Tel: 390458124872 e-mail: dr.francescobrigo@gmail.com

O2014 Turkish League Against Rheumatism. All rights reserved. 